\title{
O SU EITO DA EXPERIÊNCIA PSICANALÍTICA ENTRE O CONTINGENTE E O NECESSÁRIO
}

Mônica Assunção Costa Lima

Psicóloga do

Hospital das

Clínicas, daUFMG.

Mestre em

Psicologia, pela

UFMG (linha de

pesquisa: estudos

psicanalíticos).

RESUMO: 0 trabalho examina a hipótese de J-C. Milner que afirma que o sujeito da experiência psicanalítica, por ser correlato da ciência moderna, também o édo contingente. Busca-se verificar até que ponto tal hipótese se sustenta e checar se encontra fundamentos no pensamento lacaniano. Discutimos as categorias do contingente e do necessário, no que se refere ao inconsciente, para concluirmos que não é viável uma psicanálise exclusivamente do contingente, esta dimensão devendo ser sempre tomada em referência ao necessário.

Palavras-chave: Ciência moderna, sujeito da ciência, sujeito psicanalítico, cadeia de significados, gozo, o contingente, o necessário.

ABSTRACT: The psychoanalytic subject between the contingent and the necessary. This paper examines Milner's hypothesis in which the subject of the psychoanalytic experience, as a correlate of modern science, is a correlate of the contingency. We have investigated if this hypothesis is sustainable and if it is well founded on the Lacanian thinking. We have discussed the categories of the contingent and the necessary, relating them to the unconscious, concluding that a psychoanalysis of the contingent is not viable, because this dimension must be considered with reference to the necessary.

Keywords: Modern science, subject of science, psychoanalytic subject, chain of signifiers, jouissance, the contingent, the necessary.

0 ponto de partida deste trabalho e o pivô de seus desdobramentos são as hipóteses que se seguem. A primeira, formulada por Lacan no texto A ciência e a verdade, propõe que "0 sujeito sobre o qual operamos em psicanál ise só pode ser o sujeito da ciência" ( LACAN, 1965/ 1966, p. 858). A segunda, apresentada por Milner no livro A obra clara, constitui-se como desdobramento da primeira ao afirmar que "o sujeito sobre o qual opera a psicanálise, sendo um correlato da ciência moderna, é um correlato do contingente". (MILNER, 1995, p. 61) 
Tais proposições abrangem noções que não são triviais. Definir com rigor o sujeito sobre o qual operamos em psicanálise configura por si só uma questão embaraçosa, o mesmo podendo ser observado em relação à ciência moderna. Sendo assim, ao buscarmos articular conceitos de tal complexidade, acabamos por deixar de lado pontos esclarecedores essenciais, já que o que nos interessou foi 0 esclarecimento da conexão entre os termos designados, a saber, as relações entre a ciência, o sujeito da práxis psicanalítica e a contingência.

A hipótese de Lacan, há pouco mencionada, faz parte de um conjunto abrangente de hipóteses apresentado por ele sobre a ciência, que nada deve a al gum tipo de cientismo. É curioso que Lacan tenha, num determinado momento de sua obra, recorrido a uma doutrina da ciência para explicitar certos conceitos da psicanálise, o de sujeito por exemplo. É possível, no entanto, aquilatar a importância de tal doutrina para seu pensamento, a partir de afirmações que estabelecem a ciência moderna como condição de possi bilidade da psicanálise. A hipótese de Jean-Claude Milner faz parte de uma teoria sofisticada da ciência, extraída da leitura realizada pelo autor da obra de Lacan e podemos nos perguntar se tal teoria está intei ramente fundamentada no pensamento lacaniano.

Discutir a posição de Lacan em relação à ciência pode parecer irrelevante para alguns. Não são poucos os psicanalistas que defendem a necessidade de se enfatizar a experiência e a clínica da psicanálise, considerando com desdém todo tema que delas se distancia, o que poderia ser o caso das teses de Lacan sobre a ciência. E, assim, uma outra questão se impõe: a de saber se o doutrinal de ciência, em Lacan, é exigência da psicanál ise ou se é necessidade exterior a seu campo. Necessidade da filosofia, por exemplo, que Lacan teria introduzido no terreno psicana lítico.

A posição de Milner é de que as teses sobre a ciência são uma necessidade interna à teoria lacaniana. Elas o são, na medida em que não é possível pensar 0 sujeito, nem a experiência da psicanálise, sem nos apoiarmos nas concepções introduzidas no pensamento moderno pela ciência. (MILNER, 1991, p. 347)

Milner aproxima as teorias lacanianas do significante e do sujeito da estratégia transcendental, que consiste em despojar o objeto de suas propriedades. No processo de desnudamento, um pouco antes de o objeto deixar de ser pensável, ele ( 0 objeto) se revela como não sendo total mente vazio, nem total mente sem estrutura. As propriedades que permanecem, chamadas residuais, não podem ser outras. Se pudessem ser diferentes, o objeto deixaria de ser pensável. Elas são resultado da eliminação do contingente. Ora, se o método transcendental caracteriza-se pelo despojamento do objeto de suas propriedades empíricas e contingentes, constatando no final do processo que ainda existem propriedades, então, devemos reconhecer que a teoria do significante tem parentesco evidente com tal método. Sob este ponto de vista, a teoria do significante seria uma lógica transcendental, ou 
aquilo que a substitui. E o que vale para a teoria do significante val e também para a teoria do sujeito, já que este encontra-se incluído na definição do significante. Ora, se as teorias do significante e do sujeito constituíssem exclusivamente a doutrina lacaniana, esta se resumiria numa metafísica transcendental. Entretanto, 0 programa de Lacan é outro, pois além da teoria significante - que reduz o pensamento a suas condições mínimas - el einclui também o corpo, instância do contingente. A sexualidade se define pela contingência infinita no corpo eéo infinito quea literalização em Lacan soletra. Só assim podemos compreender, nos diz Milner, por que a teoria da ciência é necessária a Lacan. A ciência moderna, com suas expressões matemáticas que fixam em leis científicas o empírico passageiro, torna concebível a passagem do sexual contingente à estruturação simbólica necessária. Somente a ciência moderna pode elucidar a articulação entre o corpo e o significante, sem o que a teoria lacaniana se reduziria a uma metafísica. (MILNER, 1991, p. $334,345,348)$

\section{A CONCEPÇÃOdE CIÊNCIA EMLACAN}

Existem diferenças, todos sabem, entre as posições de Freud e Lacan no que se refereà ciência. Enquanto a ciência, para Freud, se coloca como ideal externo a ser alcançado pela psicanálise se esta quiser um dia conquistar o adjetivo de científica, para Lacan, ela não é ponto ideal, e nem tampouco é exterior ao campo psicanalítico. Lacan inverte a perspectiva ao afirmar que a ciência moderna mantém com a psicanálise relação de estruturação interna.

Para elucidar a relação lógica entre ciência e psicanálise devemos lançar luzes sobre as concepções dos epistemólogos que fundamentam a visão lacaniana de ciência: Koyré, Kojèvee Popper. 0 último nome é sugestão de Milner, que o designa como 0 elo ausente na cadeia lacaniana de razões ligando a ciência à psicanálise.

Segundo Koyré, a revolução científica ocorrida no século XVI deve ser considerada a mais importante revolução do pensamento humano, depois da descoberta do cosmos pelos gregos. A mudança intelectual radical estáligada às idéias de Galileu e sua expressão mais importante é a física matemática. Constitui-se como ruptura em relação às concepções científicas gregas e medievais, pois determinou a subversão do conjunto de conceitos e axiomas vigentes até então, além de introduzir uma idéia inédita da natureza, da ciência e da filosofia (KOYRÉ, 1966/ 1973, p. 166).

A novidade galileica é que a matemática, agora, estrutura a ciência. Ela pode apreender e expressar o empírico, sem considerar - como os gregos - uma hierarquia que vai dos seres menos perfeitos, rebeldes à matemática, aos seres mais perfeitos e necessários que podem ser, por essa razão, quase integralmente matematizados. A física moderna considera todos os seres como estando num mesmo nível ontológico e seu objeto é o que na natureza existe de passageiro, e de imperfeito. Desaparece toda e qual quer consideração fundada so bre o valor, a per- 
feição e a harmonia. 0 corte efetuado por Galileu implica no rompimento da matemática com o eterno e com o necessário, pois, a partir de então, ela incide, enquanto letra, na natureza, devendo apreender pelo cálculo o que ali se apresenta como mutável.

Nessa mesma direção aponta a tese proposta por Kojève (1964) , ao assinal ar a origem cristã da ciência moderna. Para o autor, existe indubitavelmente conexão entre a ciência/ técnica moderna e a teologia cristã. Ele chama a nossa atenção para o fato de que a física matemática, nascida no século XVI na Europa, não é encontrada nem antes desta data, nem tampouco fora deste espaço geográfico. Chineses, indianos, árabes, hebreus, em suma, nenhum povo não cristão foi capaz de superar a ciência helênica. A física matemática, figura proeminente da ciência moderna, surge especificamente na civilização cristã. ${ }^{1}$

Diferentemente da teologia cristã, na teologia pagã clássica, Deusé sempre transcendente. 0 Theos do paganismo clássico está sempre além do mundo onde vive 0 pagão. A tela que separa Deus do mundo é para Platão um Cosmosideal utópico e, paraAristóteles, o Céu planetário sideral. Pouco importa, o que conta é a absoluta impossi bilidade para o pagão e para Deus de franquear a barreira. 0 mundo transcendente, onde o Theos se manifesta, é um conjunto bem ordenado de relações rigorosas, fixadas desde sempre entre números eternos e precisos. Inversamente ao mundo divino, o mundo profano não comporta relações realmente matematizáveis, ou seja, relações eternas e precisas. De acordo com esta teologia, seria absurdo buscar tais leis na matéria vulgar que constitui nossos corpos, o que significa que, para eles, a física moderna é impensável.

Partindo da idéia de que a ciência moderna nasce da oposição à ciência pagã e constatando que tal oposição só surgiu no cristianismo, Kojève busca identificar o dogma cristão que fez com que os cristãos inventassem a física matemática. Conclui, em sua análise, que o único dogma exclusivamente cristão éo da encarnação, já que o monoteísmo, o criacionismo e a trindade encontram-se presentes também no judaísmo, no islamismo e no neoplatonismo.

E o que a encarnação é senão a possibilidade da presença de Deus eterno no mundo temporal onde vivemos, sem perder nada de sua perfeição? Ora, se a presença no mundo sensível não deteriora a perfeição de Deus é porque este mundo também é perfeito em alguma medida. Se, como dizem os cristãos, um corpo terrestre, humano, pode ser ao mesmo tempo o corpo de Deus, nada mais os im-

\footnotetext{
${ }^{1}$ É preciso ressaltar que este é um ponto de divergência entre Kojève e Lacan. Se o primeiro atribui ao cristianismo, e em especial ao dogma da encarnação, um papel decisivo na edificação da ciência moderna, o segundo defende o ponto de vista de que "a ciência moderna, aquela nascida de Galileu, só podia ter-se desenvolvido a partir da ideologia bíblica judaica, e não da fil osofia antiga e da perspectiva aristotélica" (LACAN. J. Le Séminaire, LivreVII, L'éhique de la psychanalyse, p. 146).
} 
pede de buscar as relações, eternas e necessárias - que de acordo com os gregos encontravam-se apenas nos corpos divinos - aqui na terra. (KOJĖE, 1964)

Ainda de acordo com o ponto de vista de Milner, o traço característico da ciência moderna para Koyré e Kojève se aproxima do apontado por Popper, se o examinamos sob o ponto de vista da contingência. Popper, como já mencionamos, seria 0 el o ausente na cadeia de razões de Lacan acerca da relação da ciência com a psicanálise. (MILNER, 1995, p. 61-62)2

Na conferência "A ciência: conjecturas e refutações", Popper está preocupado em estabelecer critérios de distinção entre as ciências e as pseudociências. Como exemplos de pseudociência, ele cita o marxismo, a psicanálise e a psicologia do indivíduo deAlfred Adler, as quais, em sua opinião, podem explicar quase tudo 0 que se passa nos campos aos quais se referem. Essas teorias, de acordo com o autor, são compatíveis com as mais divergentes condutas humanas. 0 mundo parece estar cheio de verificações de seus postulados, e os resultados das observações nunca contradizem as hipóteses. Já no caso das teorias científicas, elas são refutadas toda vez que a observação mostra a ausência do efeito que havia sido predito, o que quer dizer que el as são incompatíveis com certos resultados da observação.

Popper considera que a confirmação de uma teoria só pode advir de um teste genuíno: aquele que tem o objetivo sério, mas infrutífero, de desmenti-la. Acredita que a confirmação de um conjunto de hipóteses só é válida se for resultado de predições rigorosas. Para ele, toda ciência implica na proibição de que certas coisas aconteçam, não podendo ser considerada científica uma teoria que não é refutada por nenhum fato da observação. Isso quer dizer que, para Popper - e é o próprio autor que o resume assim - o critério de cientificidade de uma teoria éa refutabilidade.

Dizer que um enunciado científico deve ser refutável significa que ele necessita ser suscetível de entrar em conflito com observações possíveis ou concebíveis. Dito de outro modo, a negação do enunciado científico deve ser possível tanto do ponto de vista lógico quanto do ponto de vista material. Deste ângulo, então, uma

\footnotetext{
20 recurso a Popper, como já assinalamos, é iniciativa de Milner, o que pode parecer bizarro se levamos em conta as controvérsias que tal iniciativa pode gerar, como por exemplo: 1) a dificuldade de se compatibilizar as críticas de Popper a Freud e à psicanálise com a idéia de que seu pensamento é necessário a essa teoria; 2) o fato de que o restante da obra de Popper pode não se harmonizar com suas hipóteses em "Conjecturas e refutações" e 3) o fato de que a tese extraída por Milner do pensamento de Popper não se encontra explicitada em sua obra. 0 que devemos considerar, entretanto, é que a posição extraída por Milner da teoria popperiana, qual seja, a de que "não há ciência moderna senão do contingente" não depende de Popper, podendo também ser encontrada em Koyré e em Kojève. Popper, aqui, serve apenas para corroborar o que os dois filósofos já haviam, por conta própria, decifrado. Além do mais, é importante ressaltar que no Popper de "Conjecturas e refutações", encontramos de fato, em nossa opinião, elementos que sustentam a leitura realizada por Milner.
} 
proposição científica ( refutável) é uma proposição contingente. Uma proposição que pode ser diferente do que é, que pode ter outro referente.

O discurso científico moderno, matematizado - se concordamos com Milner - apreende o contingente. Este é, como vimos, um ponto comum na interpretação que ele faz dos discriminantes da ciência de Koyré, Kojève e Popper, e, sob este prisma, a matemática não extingue o acaso. As letras e números das fórmulas matemáticas não têm razões para ser como são, nem para ser diferentes do que são, mas desde que uma letra é fi xada numa equação matemática, descrevendo uma lei científica, ela permanece, não muda mais, a não ser que mudemos de equação. À permanência chamamos "a necessidade da ciência". Entretanto, a necessidade que encontramos nas leis científicas não passa de uma "cicatriz da contingência" (MILNER, 1995, p. 63), pois se acatamosa leitura que Milner faz de nossos epistemólogos, cada referente de cada proposição científica pode ser diferente do queé. 0 conjunto de pontos aos quais se referem as proposições científicas é chamado de universo. Estes pontos devem se deixar apreender numa oscilação infinita, sendo eternamente mutáveis, e é suficiente a variação de apenas um deles para que tenhamos dois universos diferentes.

Ocorre que o universo científico se define a partir da exclusão de todos os outros universos possíveis e sob este ponto de vista podemos compreender que 0 universo é necessariamente infinito. Não se trata de infinito quantitativo nem extensivo e sim qualitativo. 0 universo é infinito, porque é contingente, por poder ser infinitamente diferente daquilo que é. A infinitude sendo sua característica intrínseca. (Idem, p. 63, 64)

\section{OINFINITOE OINCONSCIENTE}

A modernidade se caracteriza pela inexistência da finitude do universo, o que significa que nada está fora dele. Podemos agora dar mais um passo e dizer: se não existe nada fora do universo, então, não existe nada fora do infinito e do contingente. $A$ idéia de que não existe nada em regime de exceção não é fácil de ser assimilada. Desde o pensamento helênico, o homem inventa figuras que se situam fora do universo: Deus, a alma - instância do homem que o associa a Deus - ea mais moderna delas, que chamamos de consciência. É neste ponto que a psicanálise ganha importância, pois é a doutrina que coloca em questão a consciência, defendendo a concepção de que existe um universo em relação ao qual nada se situa como exceção, nem mesmo o homem. 0 conceito psicanalítico que sustenta esta proposição é o conceito de inconsciente. 0 inconsciente contradiz os privilégios da consciência do homem como aquilo quefaz exceção ao Todo. A ciência e o inconsciente depõem a primazia do eu e contrariam a exceção narcísica. Assim como na ciência moderna, o infinito parasita o finito - todo finito apresenta-se, primeiramente, como podendo ser incessantemente diferente do que é - 0 in- 
consciente parasita o consciente. "Parasita-o manifestando-se como podendo ser diferente do queé, e deste modo acaba por estabelecer em que ele não pode ser de outro modo". (Idem, p. 66-67)

A semelhança averiguada por Milner entre a ciência moderna e o inconsciente encontra-se no fato de que o pensamento inconsciente, "estruturado como uma linguagem", exatamente como as leis científicas, não pode mudar. A estrutura permanece desde que a letra assim a fixou, mas não devemos nos esquecer que a letra, no inconsciente, soletra o sexual, lugar da contingência infinita no corpo. Sexual este parasitado pelo infinito que nele se presentifica sob a forma da pulsão de morte, do gozo e do "não-todo".

\section{A LETRA EMLACAN}

A noção de literalização, introduzida por Milner na discussão acerca da relação da psicanálise com a ciência, no primeiro tempo do ensino de Lacan, deve ser pensada em referência ao estruturalismo - via apresentada no século XX às ciências conjeturais como possibilidade de tratamento exato e preciso de seus objetos, a partir da matematização ampliada. Nos anos 1950, a letra e a escrita propiciam a Lacan aproximação do inconsciente e do sujeito, utilizando um número mínimo de conceitos iniciais. A letra, em sua figura de caracter tipográfico, reúne várias características que Lacan pretende atribuir ao significante. A letra nos dá prova de sua materialidade por não poder ser reduzida a unidades menores e por sua topologia específica. Na escrita, bem como na cadeia do inconsciente, as letras se organizam obedecendo a uma sintaxe que preside desde as organizações mais elementares até as mais complexas, nas quais vemos surgir possi bilidades e impossibilidades de combinação. As letras podem compor várias frases e palavras, podem ligar-se de variadas formas, e isso ocorre porque elas não possuem nenhum sentido fixado, não representam nada, não têm referente. 0 sentido advém da articulação entre elas, articulação que se faz e desfaz, possi bilitando o surgimento de novas organizações e garantindo a característica essencial do simbólico, que é a de ser perpetuamente mutável. Por último, a letra preexiste ao sujeito, bem como às regras que presi dem seu ajuntamento, o que assegura seu caráter radicalmente extrínseco e heterogêneo em relação ao ser falante.

Esclarecido o uso que Lacan faz da letra, nos referidos anos 1950, é necessário indicarmos as modificações introduzidas na concepção de linguagem no interior do seu pensamento. Se, num primeiro momento, o inconsciente edificou-se do lógico puro, posteriormente a estrutura simbólica é pensada em sua articulação ao gozo do vivente que fala.

Dois momentos da nova teorização sobre a letra devem ser privilegiados. Em primeiro lugar, "Lituraterra", texto escolhido para abrir a nova coletânea de escritos de Lacan, denominada Outros escritos. A escolha, que não é casual, pode ser ex- 
plicada por algumas razões. É provável que seja referência ao "Seminário sobre 'A carta roubada'", artigo que abre os Escritos, analisando uma obra literária. Aliás, Lacan, na introdução de "Lituraterra”, retoma num comentário o referido artigo. Os dois textos que abrem os dois Escritos situam-se num campo de relação da psicanálise com a literatura. E, mais do que isso: ambos apresentam teoria sobre a letra, "lituraterra" tratando de separar os dois termos que na "Carta roubada" mostra vam-se sobrepostos, quais sejam, a letra e o significante.

"A carta roubada" abre uma série de Escritos, cuja lição Lacan resumiu na seguinte proposição: "o inconsciente se edifica do lógico puro, dito de outro modo, do significante". É texto que está em consonância com este axioma. Já os Outros escritos enfatizam a satisfação pulsional derivada do significante. ${ }^{3}$

Assim, o fato de "Lituraterra" abrir a coletânea nos assinala que al go mudou na teoria do significante, e que a estrutura simbólica, a partir de então, deve ser pensada em sua articulação ao gozo do vivente que fala. A letra, agora investida de estatuto diferente daquele do significante (LACAN, 1971/ 2001, p. 12), deve poder responder por certos aspectos da experiência analítica, mais especificamente pela substancialidade que, no Seminário XX, Lacan associa ao gozo.

A introdução do termo lituraterra tem relação com as modificações introduzidas no ensino de Lacan em função da promoção do escrito (Idem, p. 12). Neste texto, Lacan acentua a vertente da letra que diz respeito à materialidade, ao objeto, ao lixo eao resto, em detrimento da outra vertente, em sua relação com a mensagem. À letraé dada posição de destaque, já que o significante, com seus efeitos de sentido, não resume a experiência do inconsciente. Ela é apresentada como elemento intermediário entre o que no inconsciente apresenta-se como decifrável ea substância do gozo. Isso é o que ilustra a metáfora da letra, enquanto litoral, que aloja o gozo criado pelo vazio da escrita.

Outra elaboração sobre a letra e o escrito encontra-se em "A função do escrito" , capítulo do Seminário XX, no qual Lacan destaca a dimensão do escrito que não tem a ver com a decifração e com o sentido, mas com a cifração de gozo.

Equivalendo a escrita de Joyce àquilo que os psicanalistas devem ler, Lacan assinala que, ali, temos profusão de significantes que se encavalam uns sobre os outros, obscurecendo a dimensão do significado. É difícil captar a significação de sua escrita, porque ela produz justamente multi plicidade de sentidos. 0 que Joyce opera com sua escrita é a eliminação do efeito representativo do significante, situandoo no registro da pura produção de gozo cifrado, o qual não requer nenhum efeito de significação.

A ilegibilidade do escrito, sua resistência à interpretação, nos aponta justamente para o que na letra ultrapassa a função de mensagem. 0 escrito tem função

\footnotetext{
${ }^{3}$ Vejam a contracapa dos 0 utros escritos.
} 
que não tem a ver com a decifração e com a produção de sentido e está relacionada com o que escapa ao discurso. A letra, diferente do significante, faz referência ao que não pode ser lido, à impossibilidade de tudo se escrever. Se do significante decorre efeito de sentido, da letra é derivado um efeito de gozo, já que ela concerne "a coisa" que não se traduz numa inscrição.

As modificações operadas na concepção da estrutura simbólica constituinte do inconsciente nos interessa porque o segundo momento teórico, em Lacan, é mais propício para desenvolvermos a hipótese de Milner, já que, ali, Lacan se esforça para conciliar a estrutura de linguagem - do registro da necessidade - com 0 sexual, que, sob certos aspectos, pode ser pensado na dimensão da contingência.

\section{OSEXUAL NA TEORIA DA PSICANÁLISE}

É chegado, pois, o momento de elucidarmos o que Milner designa como sexual. Todos sabem que o conceito de pulsão é introduzido por Freud especificamente no contexto do sexual, enquanto anteriormente ele só havia falado de energia psíquica. 0 sexual em psicanálise encontra-se, desde 1905, com os Três ensai os, associado ao contentamento das pulsões eà satisfação extraída do próprio corpo. À sexualidade perversa polimorfa - caracterizada pela atividade auto-erótica das pulsões parciais, que recortam o corpo em zonas erógenas - é acrescentada, entretanto, na teorização acerca do complexo de Édipo, a problemática do falo, da castração e da lei do pai. Podemos dizer que a vivência edípica é o momento no qual o inconsciente se estrutura em resposta às excitações corporais, vivenciadas na sexualidade infantil. Ocasião em que a linguagem é convocada para interpretar o gozo oriundo das diferentes zonas erógenas, sobretudo as sensações genitais, que, neste período, apresentam-se intensas e perturbadoras.

$\mathrm{Na}$ encruzilhada do Complexo de Édipo, à sexualidade perverso polimorfa impõe-se uma forma, um curso. A satisfação sexual primária que se apresentou, inicialmente, como perturbadora, indefinível e podendo ocorrer de infinitos modos, é organizada, neste momento, em referência ao primado do falo. 0 recalcamento das pulsões parciais, efetuado na dissolução do complexo de Édipo, tem por efeito a substituição do gozo do corpo pela sexualidade comandada pela linguagem. 0 recalque transforma em gozo sexual - no sentido específico que ele assume para o ser falante - o que, anteriormente, fora experimentado como sensação indeterminada.

A promoção do falo, efetuada por Lacan, ao estatuto de significante privilegiado capaz de organizar um campo de significação referente ao sexual é decorrente da tese freudiana do primado do falo, segundo a qual, tanto o menino quanto a menina toma conhecimento de seu sexo a partir do significante fálico. 0 significado desta tese é que o sexo no ser humano se determina não segundo dado anatômico, mas segundo a relação do sujeito com a castração. Fazendo com que não 
haja complementaridade possível na relação homem e mulher e sim disparidade, dissimetria fundamental.

Embora Freud tenha explicado satisfatoriamente a constituição do masculino a partir da ameaça de castração e da dissolução do complexo de Édipo, o feminino, ao que parece, mostrou-se sempre rebelde em adequar-se a este modelo - a mulher tendo permanecido, para a psicanálise, como enigma, como inclassificável, como o que resiste à castração e a qualquer tipificação sob um significante único.

Assim, pois, é partindo do impasse, alcançado por Freud, na tentativa de explicar a feminilidade nos moldes da castração que podemos retomar a rel eitura feita por Lacan do complexo de Édipo freudiano a partir das fórmulas quânticas da sexuação. Com as fórmulas, Lacan busca discernir dois tipos de gozo: um interditado pelo significante e ligado ao ser e outro permitido pelo significante e ligado à significação fálica. Desloca a pergunta sobre a sexualidade feminina para uma pergunta sobre o gozo. 0 masculino e o feminino, em sua elaboração, tornam-se dois tipos de gozo e a questão que se abre é a de saber se existe gozo para além do falo.

Lacan propõe a idéia de que o feminino não se submete completamente ao Édipo nem à castração, destacando os efeitos do primado do falo, para a mulher, como divisão nela operada. A mulher, para Lacan, está "não-toda" na função fálica e écapaz de experimentar outro tipo de satisfação que floresce à margem da estrutura organizada pelo falo.

$O$ verdadeiro interesse de Lacan, no Seminário XX, éo de abrir uma via do "nãotodo" por intermédio de nova formalização da sexualidade feminina. Como a função fálica é insuficiente para recobrir todo o campo das pulsões, ocorre fracasso na unificação destas numa pulsão sexual global que dê conta da relação ao Outro sexo, o qual não é representado por significante nenhum.

Deste modo, ao lado da satisfação que se organiza sob o primado do falo, persiste uma outra que resiste a unificar-se sob esta função, mantendo sua alteridade em relação ao gozo fálico e preservando a marca de sua contingência e de sua nãototalização. E, aqui, encontramos o infinito na absoluta contingência de que nos fala Milner, que não se define, que não se delimita num universo fechado. 0 infinito parasita a função fálicae, apesar denos esquecermos dele, diante da necessi dade que se instaura em função da determinação do sujeito pelo significante, ele persevera em sua presença silenciosa acoplado à estrutura de linguagem presidida pelo falo.

\section{OSUJ EITO, OINFINITOE A CONTINGÊNCIA}

Badiou (1993, p. 18-31), no texto Suje to einfinito, discute dois parágrafos do Seminário XX que o intrigaram durante muito tempo. Neles, Lacan coloca em evidência que a condição fundamental para as fórmulas da sexuação é a condição de infinitude. Nas mencionadas fórmulas, embora a função fálica ou de castração seja um 
argumento obrigatório, válido para todos, ela pode operar de dois modos diferentes. Pode ser ou não ser de al cance absolutamente universal. 0 enunciado "para todo $x,(x)$ ", em função do "para todo" nos insere no universal da castração, enquanto que o enunciado "não-todo $x(x)$ " coloca restrição parcial para a operação de castração. A mulher está "não-toda" no gozo fálico.

Na lógica aristotélica, a negação de uma universal implica sempre numa particular. Se dizemos "não todo homem é mortal", então, necessariamente "algum homem é imortal". Se fôssemos aristotélicos, no caso das fórmulas da sexuação teríamos: se "não-todo x (x)", então, "existe um x como não (x)". Essa é precisa mente a dificuldade que Lacan quer evitar, pois ele não pode admitir que exista al gum sujeito subtraído à função da castração. A castração é universal, está identificada à função da linguagem. 0 que $(x)$ significa é que o sujeito não pode mais dispor do conjunto de significantes, que para ele a língua é "não-toda". Admitir um sujeito que não se relacione com a função da castração é o mesmo que admitir que tal sujeito não se encontra na linguagem.

Ao definir a posição da mulher como "não-todo $x(x)$ ", Lacan ressalta que não devemos tomar a fórmula em extensão. Ou seja, a fórmula não significa que al gumas mulheres estejam subtraídas à função $(x)$ e, sim, que não é do ponto do todo que a mulher sustenta a função. A fórmula indica apenas uma brecha neste efeito, que está em alguma parte e não em toda parte.

A solução encontrada por Lacan, segundo Badiou, está do lado do infinito. Lacan nos diz que se o "não-todo" operasse no finito, produziria como efeito "existe um como não", ou seja, a desuniversal ização da castração, exatamente como vimos na lógica clássica. É preciso então supor que o campo onde opera o "nãotodo" seja infinito. Tal campo é o do gozo feminino, o que nos leva a concluir que o gozo feminino é infinito. 0 infinito está afetado em "al guma parte" pela função da castração. Apenas em al guma parte, pois, a função fálica diante do infinito fracassa em estar em "toda parte" . Já dissemos que a castração se apóia no fato de a língua só ser disponível de modo finito, como língua "não-toda" , o quenoslevaa concluir que o gozo queé da ordem do infinito, queultrapassa o registro fálico, é gozo que está fora da linguagem.

0 embaraço de Lacan está em evitar que o gozo suplementar da mulher ateste uma ex-istência ao efeito da castração. Lembrem-se que Lacan não abre mão do universal da castração e luta até o fim com a conseqüência existencial do "nãotodo", mencionada acima. Sendo assim, a solução apontada por Badiou, a que Lacan teria encontrado, é a seguinte: temos o gozo fálico, determinado de modo finito pela função $(x)$; este gozo está em algum lugar, e pode, por esta razão, ser circunscrito. Temos também o outro gozo, por meio do qual a posição da mulher se sustenta pelo "não-todo". Contudo, como a alteridade é da ordem do infinito, não podemos pensá-la como existência que negue a castração, ela é, como diz 
Lacan, muito indeterminada para isso. Uma existência que negue a castração teria que ser finita, determinada e circunscrita. 0 suplemento feminino é infinito e como tal não complementa o primeiro gozo, o gozo fálico, como conjunto determinado. Eleé sem contorno e como tal não inclui nenhuma existência que proceda da negação do primeiro gozo. Lacan em ...ou pire define o "não-todo" como "aquele que não está contido na função fálica sem no entanto ser sua negação" ( LACAN, apud BADIOU), no que reconhecemosuma exterioridade que não é negação. Assim, segundo Badiou, o infinito proíbe que a relação entre os dois gozos seja dialética, que seja a união dos contrários ou ainda uma relação. 0 infinito introduz uma dissimetria que torna impossível a rel ação entre o "para-todo" homem com a"não-toda" mulher.

Assim, retomando o que já foi dito, a condição para que o gozo feminino não se constitua numa negação da função fálica nem na afirmação da existência de al gum sujeito que negue a castração, é que ele seja infinito e indefinido. Este é o infinito de que nos fala Milner. Infinito que não se define, que não se delimita num universo fechado, eis o que a letra no inconsciente soletra. 0 infinito parasita a função fálica e, apesar de nos esquecermos dele, diante da necessidade que se instaura sob a forma da determinação do sujeito pelo significante, ele persevera em sua presença silenciosa, acoplado à estrutura de linguagem.

Na noção ampla de gozo, em Lacan, localizamos a noção mais restrita do gozo sexual. 0 gozo sexual fálico limita o gozo em geral. Do gozo do ser a função fálica tem por efeito nos separar. 0 gozo sexual abre-se como possibilidade para o ser falante a partir da castração e do submetimento à estrutura de linguagem. Está irrevogavelmente ligado ao falo e pode ser traduzido na cadeia significante nos termos do desejo. Se a sexualidade infantil se resume na satisfação pulsional autoerótica, alcançada em torno das zonas erógenas, a pulsão sexual propriamente dita volta-se para o Outro sexo e para a castração. 0 gozo sexual ocorre exclusivamente por meio de semblantes, enquanto o "gozo do Outro", como o chamou Lacan no Seminário XX, é fora da linguagem, disjunto da existência do sujeito na cadeia significante.

$\mathrm{Na}$ idéia de Milner de que o inconsciente soletra o sexual em sua dimensão infinita está implicada esta dupla face. Alguma coisa do sexual pode se inscrever, é o caso da função fálica demarcando um masculino e um feminino. É o caso do fantasma, que, numa frase, escreve algo da relação do sujeito com seu objeto de satisfação. No entanto, a outra face da escrita do sexual - que determina de modo necessário uma posição subjetiva - é o gozo infinito, quea função fálica, por sua insuficiência, não pôde delimitar, permanecendo, assim, em sua dimensão contingente.

Buscamos o gozo obtido na primeira experiência de satisfação, mas o gozo fálico é o que se produz na repetição significante necessária. Este não seria necessá- 
rio se a relação sexual existisse. Tudo seria bem mais harmonioso se pudéssemos nos satisfazer como na situação mítica do primeiro encontro com o objeto. Se o outro gozo fosse possível, não seria necessário o gozo fálico. Ele não seria necessário - tempo condicional - contudo, ele o é. 0 gozo fálico torna-se necessário e este éo correlato da afirmação de que não existe relação sexual. 0 "Outro gozo" , 0 que não convém à ausência de relação sexual no ser falante éo que sofrea incidência do recalque. Não é necessário, permanecendo subtraído da inscrição significante, preservando sua face de impossível.

Afirmar que a mulher é "não-toda" é reconhecer a existência de um gozo da ordem do infinito que permanece al heio ao falo e em regime de exceção. É considerar que o que da ordem do sintoma se inscreve, de modo necessário, funda-se numa contingência corporal. Este enlaçamento éo que se encontra em questão no inconsciente de Milner que se institui como literalização do sexual contingente, nos fazendo admitir que, numa análise, não trilhamos apenas a vertente do desejo, enquanto repetição significante. 0 que o discurso analítico nos indica, justamente, é a direção na qual o sentido sexual, enquanto semblante, fracassa.

\section{CONCLUSÃO}

Assim, acreditamos poder afirmar a pertinência e a coerência da hipótese de JeanClaude Milner, que sustenta que o sujeito da experiência analítica, por ser correlato da ciência moderna, é correlato do contingente. 0 sujeito de que falamos é 0 sujeito suposto ao inconsciente, instituído a partir da "literal ização" do sexual. Do mesmo modo que a ciência fixa o empírico passageiro e mutável nas leis científicas, enunciadas em equações compostas por letras e números, o encontro causal do sujeito com o Outro faz surgir a inscrição corpórea da satisfação sexual sob a égide da letra. Tal satisfação só se define como resultado da incidência da letra que recorta o organismo, fazendo surgir um corpo. 0 sexual contingente é o gozo que permanece fora da linguagem, alheio às relações necessárias da estrutura, fazendo fronteira com o gozo fálico que se tornou necessário. Pode configurar-se numa infinidade de maneiras possíveis. Este é o inconsciente que pode ser diferente do queé, universo que permanece aberto e indefinido.

A noção de sujeito proposta por Milner - sujeito da ciência, correlato do contingente - não toma como referência apenas o pensamento, não se reporta somente ao "inconsciente estruturado como uma linguagem". Amplia a leitura que, visando demonstrar a equival ência entre o sujeito da ciência e o sujeito da psicanálise, aponta para asimilaridade entre o pensamento inconsciente - funcionando como sistema coerente de letras que não possuem nelas mesmas sentido algum - e o pensamento da ciência moderna - que traduz o empírico com fórmulas matemáticas. A interpretação do sujeito, proposta por Milner, toma em consideração, além do pensamento - reduzido a suas propriedades mínimas e 
necessárias - o gozo contingente, sendo compatível com o ensino de Lacan, sobretudo com as elaborações apresentadas na década de 1970.

Neste período, Lacan, sem abrir mão da dimensão necessária da estrutura de linguagem, prioriza progressivamente 0 aspecto contingencial do sujeito. Passa a enfatizar a parte do sujeito não apreendida pelo significante, o que podemos constatar nos desenvolvimentos das figuras do "não-todo", do infinito, do gozo do Outro, do gozo do corpo, do ser, etc.

O sujeito da práxis psicanalítica é o sujeito da ciência, não apenas porque a estrutura de linguagem do inconsciente se assemelha à estrutura do discurso da ciência, mas, também, porque as letras do inconsciente são "cicatrizes do contingente". A letra torna eterno e necessário o que se modifica incessantemente. $\mathrm{E}$, deste modo, podemos concluir que as concepções tardias de Lacan acerca do sujeito, do sintoma e da linguagem, em psicanálise, representam não somente a reafirmação da relação lógica entre psicanálise e ciência, como, também, o desenvolvimento, até as últimas conseqüências, desta hipótese. Quanto à pergunta, colocada no início do trabal ho - que questionava se a ciência é necessidade interna à teoria da psicanálise ou se é necessidade da filosofia, introduzida por Lacan no terreno psicanalítico - devemos ressaltar que a hipótese segundo a qual a ciência moderna éo que garante, na teorialacaniana, a conexão entreo sexual e a teoria do significante é de Milner e não de Lacan, já que este nunca explicou as razões queo levaram a recorrer a uma doutrina da ciência para explicitar conceitos psicanalíticos. E o que podemos afirmar é que, no desenvolvimento do trabalho, ela deu provas de sua congruência. De qualquer maneira, se aceitamos a hipótese como verdadeira, temos que admitir que o "doutrinal de ciência" é necessário apenas ao pensamento lacaniano, pois, muito claramente, Freud encontrou outra forma de sulcar o caminho para a psicanál ise. Elucidar que caminho foi este pode ser o objeto de outra pesquisa. Nesta discussão, no entanto, é essencial considerarmos a diferença entre as teses sobre a ciência como necessárias à teoria da psicanálise, ea ciência moderna, como condição de possi bilidade da teoria da psicanálise. 0 fato de Freud não ter recorrido a uma teoria da ciência para elaborar seu conceito de inconsciente, não é incompatível com a idéia da ciência como condição para a concepção deste mesmo inconsciente.

$\mathrm{Na}$ teoria lacaniana da ciência, que até aqui nos serviu como guia, o que se encontra no cerne da relação entre ciência e psicanálise, consistindo na lógica desta relação, independente de todo e qualquer discurso persuasi vo, éa idéia do corte discursivo instaurado, com a emergência da ciência moderna. Este corte, na modernidade, afetou todos os discursos compatíveis, sem que nenhum discurso tenha permanecido imune. N em mesmo a subjetividade, o que nos indica a hipótese do sujeito da ciência.

Sob este ponto de vista podemos, então, afirmar que o discurso freudiano, 
sendo discurso moderno, sofre os efeitos disseminados pela ruptura ocasionada pela ciência moderna, independentemente do fato de Freud ter ou não recorrido a teses sobre a ciência para organizar seu campo conceitual

Por último, gostaríamos de ressaltar que a ênfase progressiva colocada, por Lacan, sobre 0 aspecto contingencial do sujeito em detrimento de sua determinação significante necessária, não implica a instalação definitiva da psicanálise na dimensão do contingente. Na realidade, em Lacan, o necessário não se opõe ao contingente. A determinação simbólica não faz oposição ao acaso, mas é dele derivada. Se, no Seminário XX, Lacan ressalta o fracasso do corte operado pelo falo, na tentativa de recobrir com significação sexual todo o campo da pulsão, e se ele destaca as fissuras encontradas na total ização operada pela função fálica, que é sempre ultrapassada e deslocada, isso não implica nenhuma desconsideração para com o falo. Ao contrário, a presença do falo é o que nos permite identificar a ausência desta medida numa parte do campo feminino. Do mesmo modo, na vertente masculina das fórmulas da sexuação, o todo se fecha numa correlação com um elemento que a ele escapa - o pai do gozo absoluto. Elemento que não se submete à função fálica, mas que se destaca a partir de um todo fálico.

Quando a psicanálise aponta para a contingência, como dimensão constituinte do sujeito, seu interesse não é promover o indecidível. Apesar de a psicanálise reconhecer os limites da função fálica, ela opera com sua positividade. 0 que se apresenta como horizonte para sua prática não é a intenção de subverter a total ização, nem a de destacar os pontos em que seu fracasso se anuncia. Ela se interessa, de preferência, por explicar a possibilidade de um efeito de ancoramento num fluxo disperso. Por produzir efeitos sobre o gozo intervindo com o simbólico. 0 que pode ser interpretado ( para retomarmoso tema de nosso trabal ho) na afirmação de que não existe psicanálise do contingente - o contingente na experiência analítica devendo sempre ser tomado em referência ao necessário.

Recebido em 26/ 4/ 2002. Aprovado em 10/ 5/ 2002.

\section{REFERÊNCIAS}

BADIOU, A. (1993) "Sujeito e infinito", ("Transferência, fantasma, direção da cura" ). Revista da Letra Freudiana, ano XII, n. 14, Rio de Janeiro, Espaço e Tempo.

FINK, B. (1998) 0 sujeito lacaniano: entre linguagem e gozo, Rio de Janeiro, Jorge Zahar.

FREU D, S. (1996) Edição standard brasi leira das obras psi cológi cas completas deSi gmund Freud, Rio de Janeiro, Imago. 
(1905) "Três ensaios sobre a teoria da sexualidade", v. VII, p. 119218.

(1923) “A organização genital infantil (Uma interpolação na teoria da sexualidade)", v. XIX, p. 155-161.

(1924) "A dissolução do complexo de Édipo", v. XIX, p. 189-200.

(1925) "Algumas conseqüências psíquicas da distinção anatômica entre os sexos, v. XIX, p. 271-286.

(1931) "Sexualidade feminina", v. XXI, p. 229-243.

KOJĖVE, A. (1964) "L'origine chrétienne da la science moderne", in Recuél d'articles, mélanges de Alexandre Koyré, v. 2, Paris, Hermann.

KOYRÉ, A. (1966/ 1973) "Galilée et Platon", in Études d'histoire de la pensée scientifique. Paris, Gallimard.

. (1957/ s/ d.) Do mundo fechado ao universo infinito. Lisboa, Gradiva.

LACAN, J. (1966) Écrits. Paris, Éditions du Seuil.

(1953) "Fonction et champ de la parole et du langage".

(1955) "Le séminaire sur 'La Lettre volée'".

(1957) “L'instance de la lettre dans l'inconscient ou la raison depuis Freud".

(1958) "La signification du phalus".

(1965) "La science et la vérité".

(2001) Autres écrits, Paris, Éditions du Seuil.

(1971) "Lituraterre".

(1972) "L'Étourdit".

MILNER, J-C. (1995) L'oeuvre claire, Paris, Éditions du Seuil.

. (1991) "Lacan et la science moderne", in Lacan avec les philosophes,

Paris, Albin Michel.

MOREL, G. (2000) Ambiguités sexuelles, Paris, Anthropos.

M ônica Assunção Costa Lima

RuaVenezuela, 598 Sion

30315-250 Belo Horizonte MG

Tel (31) 3285-1589 / 9977-1372

monicacl@pib.com.br 